\title{
Analysis of One-Bond Se-Se Nuclear Couplings in Diselenides and 1,2-Diselenoles on the Basis of Molecular Orbital Theory: Torsional Angular Dependence, Electron Density Influence, and Origin in ${ }^{1} J($ Se, Se $)$
}

\author{
Akito Tanioku, Satoko Hayashi, and Waro Nakanishi \\ Department of Material Science and Chemistry, Faculty of Systems Engineering, Wakayama University, 930 Sakaedani, \\ Wakayama 640-8510, Japan \\ Correspondence should be addressed to Waro Nakanishi, nakanisi@sys.wakayama-u.ac.jp
}

Received 19 January 2009; Revised 15 April 2009; Accepted 8 May 2009

Recommended by Vito Lippolis

Nuclear couplings for the Se-Se bonds, ${ }^{1} J(\mathrm{Se}, \mathrm{Se})$, are analyzed on the basis of the molecular orbital (MO) theory. The values are calculated by employing the triple $\zeta$ basis sets of the Slater type at the DFT level. ${ }^{1} J(\mathrm{Se}, \mathrm{Se})$ are calculated modeled by MeSeSeMe (1a), which shows the typical torsional angular dependence on $\phi\left(\mathrm{C}_{\mathrm{Me}} \mathrm{SeSeC}_{\mathrm{Me}}\right)$. The dependence explains well the observed ${ }^{1} J_{\text {obsd }}(\mathrm{Se}, \mathrm{Se})$ of small values $(\leq 64 \mathrm{~Hz})$ for RSeSeR' $(\mathbf{1})$ (simple derivatives of 1a) and large values $(330-380 \mathrm{~Hz})$ observed for 4-substituted naphto $[1,8-c, d]$-1,2-diselenoles (2) which correspond to symperiplanar diselenides. ${ }^{1} J$ (Se, Se : 2 ) becomes larger as the electron density on Se increases. The paramagnetic spin-orbit terms contribute predominantly. The contributions are evaluated separately from each $\mathrm{MO}\left(\psi_{i}\right)$ and each $\psi_{i} \rightarrow \psi_{a}$ transition, where $\psi_{i}$ and $\psi_{a}$ are occupied and unoccupied MO's, respectively. The separate evaluation enables us to recognize and visualize the origin and the mechanism of the couplings.

Copyright (c) 2009 Akito Tanioku et al. This is an open access article distributed under the Creative Commons Attribution License, which permits unrestricted use, distribution, and reproduction in any medium, provided the original work is properly cited.

\section{Introduction}

Indirect nuclear spin-spin coupling constants $(J)$ provide highly important information around coupled nuclei, containing strongly bonded and weakly interacting states, since the values depend on the electron distribution between the nuclei $[1-10]$. One-bond $\left({ }^{1} J\right)$, two-bond (geminal) $\left({ }^{2} J\right)$, three-bond (vicinal) $\left({ }^{3} J\right)$, and even longer coupling constants $\left({ }^{n} J(n \geq 4)\right)$ are observed between selenium atoms, which will give important information around the coupled nuclei. The mechanism for ${ }^{1} J$ must be of the through-bond type; however, that for ${ }^{n} J(n \geq 2)$ would contain through-space interactions, especially for ${ }^{n} J(n \geq$ 4). Quantum chemical (QC) calculations are necessary for the analysis and the interpretation of the $J$ values with physical meanings. Important properties of molecules will be clarified by elucidating the mechanism of spin-spin couplings on the basis of the molecular orbital (MO) theory.
Various ${ }^{1} J_{\text {obsd }}($ Se, Se) values are reported for alkyl and/or aryl derivatives of dimethyl diselenide (1a) (RSeSeR': 1). They are usually small $\left({ }^{1} J_{\text {obsd }}(\right.$ Se, Se: 1$) \leq 64 \mathrm{~Hz}$; see Table 1$)$. We examined ${ }^{1} J$ (Se, Se) of naphto[1,8-c,d]-1,2diselenole (4-Y-1,8- $\mathrm{Se}_{2} \mathrm{C}_{10} \mathrm{H}_{5}$ (2): $\mathrm{Y}=\mathrm{H}$ (a) [11-15], OMe (b), $\mathrm{Me}(\mathbf{c}), \mathrm{Cl}(\mathbf{d}), \mathrm{COOMe}(\mathbf{e}), \mathrm{CN}(\mathbf{f})$, and $\left.\mathrm{NO}_{2}(\mathbf{g})\right)$, which correspond to the symperiplanar diselenides (Figure 1). The ${ }^{1} J(\mathrm{Se}, \mathrm{Se})$ values are measured for $2 \mathrm{c}, 2 \mathbf{d}$, and $2 \mathrm{~g}$, and large ${ }^{1} J_{\text {obsd }}(\mathrm{Se}, \mathrm{Se})$ values of $330-380 \mathrm{~Hz}$ are detected. Table 1 summarizes the ${ }^{1} J_{\text {obsd }}(\mathrm{Se}, \mathrm{Se})$ values.

Why are ${ }^{1} J_{\text {obsd }}$ (Se, Se: 2$)$ much larger than ${ }^{1} J_{\text {obsd }}($ Se, Se: 1)? How do ${ }^{1} J_{\text {obsd }}($ Se, Se: 2$)$ depend on the substituent $Y$ in 2 ? $^{1} J$ ( $\mathrm{Se}, \mathrm{Se}$ ) are analyzed on the basis of the MO theory, as the first step to investigate the nature of the bonded and nonbonded interactions between selenium atoms through ${ }^{n} J(\mathrm{Se}, \mathrm{Se})[18] .{ }^{1} J(\mathrm{Se}, \mathrm{Se})$ are calculated for $\mathbf{1 a}$ and $\mathbf{2} \mathbf{a}-\mathbf{g}$.

According to the nonrelativistic theory, there are several mechanisms contributing to the spin-spin coupling constants. As expressed in (1), the total value $\left({ }^{n} J_{\mathrm{TL}}\right)$ is composed 
TABle 1: Observed ${ }^{1} J_{\text {obsd }}(\mathrm{Se}, \mathrm{Se})$ values of some selenium compounds.

\begin{tabular}{lcc}
\hline Compound & ${ }^{1} J_{\text {obsd }}(\mathrm{Se}, \mathrm{Se})[\mathrm{Hz}]$ & Comment \\
\hline$t \mathrm{BuSeSeMe}$ & 2.7 & $(\mathrm{a})$ \\
$n \mathrm{BuSeSeMe}$ & 36.3 & $(\mathrm{a})$ \\
$\mathrm{MeSeSePh}$ & 22 & $(\mathrm{a})$ \\
$o-\mathrm{O}_{2} \mathrm{NC}_{6} \mathrm{H}_{4} \mathrm{SeSeCN}$ & 64 & $(\mathrm{~b})$ \\
$\mathbf{2}(\mathrm{Y}=\mathrm{Me})$ & 379.4 & This work \\
$\mathbf{2}(\mathrm{Y}=\mathrm{Cl})$ & 375.9 & This work \\
$\mathbf{2}\left(\mathrm{Y}=\mathrm{NO}_{2}\right)$ & 330.8 & This work \\
\hline
\end{tabular}

(a) References $[9,16]$.

(b) References $[9,17]$.

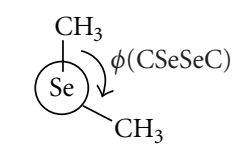

MeSeSeMe (1a) RSeSeR' (1)

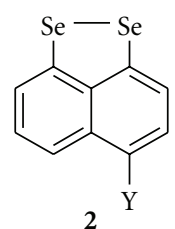

2

\begin{tabular}{cccccccc}
\hline & $\mathbf{a}$ & $\mathbf{b}$ & $\mathbf{c}$ & $\mathbf{d}$ & $\mathbf{e}$ & $\mathbf{f}$ & $\mathbf{g}$ \\
\hline $\mathrm{Y}:$ & $\mathrm{H}$ & $\mathrm{OMe}$ & $\mathrm{Me}$ & $\mathrm{Cl}$ & $\mathrm{COOMe}$ & $\mathrm{CN}$ & $\mathrm{NO}_{2}$ \\
\hline
\end{tabular}

FIGURE 1 of the contributions from the diamagnetic spin-orbit (DSO) term $\left({ }^{n} J_{\mathrm{DSO}}\right)$, the paramagnetic spin-orbit (PSO) term $\left({ }^{n} J_{\mathrm{PSO}}\right)$, the spin-dipolar (SD) term $\left({ }^{n} J_{\mathrm{SD}}\right)$, and the Fermi contact $(\mathrm{FC})$ term $\left({ }^{n} J_{\mathrm{FC}}\right)$,

$$
{ }^{n} J_{\mathrm{TL}}={ }^{n} J_{\mathrm{DSO}}+{ }^{n} J_{\mathrm{PSO}}+{ }^{n} J_{\mathrm{SD}}+{ }^{n} J_{\mathrm{FC}} .
$$

Scheme 1 summarizes the mechanism of the indirect nuclear spin-spin couplings. The origin of the terms, ${ }^{n} J_{\mathrm{DSO}}$, ${ }^{n} J_{\mathrm{PSO}},{ }^{n} J_{\mathrm{SD}}$, and ${ }^{n} J_{\mathrm{FC}}$, is also illustrated, contributing to ${ }^{n} J_{\mathrm{TL}}$. The ground state of a molecule $(\boldsymbol{M})$ is the singlet state $\left(S_{0}\right)$ if the nuclei $(N)$ in $\boldsymbol{M}$ have no magnetic moments. However, the ground state cannot be the pure $S_{0}$ if $N$ possesses magnetic moments, $\mu_{N}$. The ground state perturbed by $\mu_{N}$ is expressed as follows: DSO arise by the reorganization of $S_{0}$; therefore, they are usually very small. PSO appears by the mixing of upper singlet states $\left(S_{1}, S_{2}, S_{3}, \ldots\right)$. FC and $\mathrm{SD}$ originate if admixtures occur from upper triplet states $\left(T_{1}, T_{2}, T_{3}, \ldots\right)$, where only s-type atomic orbitals contribute to FC.

Calculated ${ }^{1} J_{\mathrm{TL}}$ values are evaluated separately by the four components as shown in (1). The ${ }^{1} J(\mathrm{Se}, \mathrm{Se})$ values are evaluated using the Slater-type atomic orbitals, which are equipped in the ADF 2008 program [19-23]. Evaluations of the values are performed employing the ADF program, after structural optimizations with the Gaussian 03 program [24]. Contributions from each $\psi_{i}$ and each $\psi_{i} \rightarrow \psi_{a}$ transition are evaluated separately, where $\psi_{i}$ and $\psi_{a}$ denote occupied and unoccupied MOs, respectively. The treatment enables us to recognize and visualize clearly the origin of the indirect nuclear spin-spin couplings.

\section{Experimental}

2.1. Materials and Measurements. Manipulations were performed under an argon atmosphere with standard vacuumline techniques. Glassware was dried at $130^{\circ} \mathrm{C}$ overnight. Solvents and reagents were purified by standard procedures as necessary. Melting points were measured with a YanacoMP apparatus of uncorrected. Flash column chromatography was performed on silica gel (Fuji Silysia PSQ-100B), acidic and basic alumina (E. Merck).

NMR spectra were recorded at $297 \mathrm{~K}$ in $\mathrm{CDCl}_{3}$ and DMSO- $d_{6}$ solutions. ${ }^{1} \mathrm{H},{ }^{13} \mathrm{C}$, and ${ }^{77} \mathrm{Se}$ NMR spectra were measured at $300,75.5$, and $76.2 \mathrm{MHz}$, respectively. Chemical shifts are given in ppm relative to those of TMS for ${ }^{1} \mathrm{H}$ and ${ }^{13} \mathrm{C}$ NMR spectra and relative to reference compound $\mathrm{Me}_{2} \mathrm{Se}$ for ${ }^{77}$ Se NMR spectra.

2.2. Preparation of 4-methylnaphtho[1,8-c,d]-1,2diselenole (2b). According to a method similar to that previously reported for $\mathbf{2 a}$ [11-17] from 1,8-dichloro-4methylnaphthalene, $\mathbf{2} \mathbf{b}$ was obtained as purple needles in $68 \%$ yield, m.p. $127.0-128.0^{\circ} \mathrm{C} .{ }^{1} \mathrm{H}$ NMR $\left(\mathrm{CDCl}_{3}\right.$, $300 \mathrm{MHz}, \mathrm{TMS}): \delta 2.50(\mathrm{~s}, 3 \mathrm{H}), 7.09(\mathrm{dd}, 1 \mathrm{H}, J=0.9$ and $7.6 \mathrm{~Hz}), 7.25(\mathrm{~d}, 1 \mathrm{H}, J=7.3 \mathrm{~Hz}), 7.36(\mathrm{dd}, 1 \mathrm{H}, J=0.6$ and $6.9 \mathrm{~Hz}), 7.55(\mathrm{dd}, 1 \mathrm{H}, J=0.7$ and $8.4 \mathrm{~Hz}) ;{ }^{13} \mathrm{C}$ NMR $\left(\mathrm{CDCl}_{3}, 75.5 \mathrm{MHz}\right.$, TMS): $\delta 18.6,120.4,120.7,121.0,127.4$, $128.2,130.4,137.0,137.3,138.0,141.1 ;{ }^{77} \mathrm{Se} \mathrm{NMR}\left(\mathrm{CDCl}_{3}\right.$, 76.2 MHz, $\mathrm{Me}_{2} \mathrm{Se}$ ): $\delta 411.8,420.6$. Anal. Calc. for $\mathrm{C}_{11} \mathrm{H}_{8} \mathrm{Se}_{2}$ : C, 44.32; H, 2.70\%; found: C, 44.21; H, 2.63\%.

2.3. Preparation of 4-chloronaphtho[1,8-c,d]-1,2-diselenole (2c). According to a method similar to that previously reported for 2a [11-17] from 1,4,8-trichloronaphthalene, 2c was obtained as brown needles in 58\% yield, m.p. 155.0 $156.0^{\circ} \mathrm{C} .{ }^{1} \mathrm{H}$ NMR $\left(\mathrm{CDCl}_{3}, 300 \mathrm{MHz}, \mathrm{TMS}\right): \delta 7.24(\mathrm{~d}, 1 \mathrm{H}$, $J=8.1 \mathrm{~Hz}), 7.30(\mathrm{~d}, 1 \mathrm{H}, J=7.9 \mathrm{~Hz}), 7.34(\mathrm{t}, 1 \mathrm{H}, J=7.7 \mathrm{~Hz})$, $7.39(\mathrm{dd}, 1 \mathrm{H}, J=1.2$ and $7.4 \mathrm{~Hz}), 7.81(\mathrm{dd}, 1 \mathrm{H}, J=1.3$ and $7.9 \mathrm{~Hz}) ;{ }^{13} \mathrm{C}$ NMR $\left(\mathrm{CDCl}_{3}, 75.5 \mathrm{MHz}\right.$, TMS $): \delta 120.5$, 120.6, 121.9, 127.3, 127.4, 128.6, 135.0, 138.5, 140.0, 141.2; ${ }^{77} \mathrm{Se} \mathrm{NMR}\left(\mathrm{CDCl}_{3}, 76.2 \mathrm{MHz}, \mathrm{Me}_{2} \mathrm{Se}\right): \delta$ 422.6, 444.6. Anal. Calc. for $\mathrm{C}_{10} \mathrm{H}_{5} \mathrm{Se}_{2} \mathrm{Cl}$ : C, $37.71 ; \mathrm{H}, 1.58 \%$; found: C, $37.83 ; \mathrm{H}$, $1.60 \%$.

2.4. Preparation of 4-nitronaphtho[1,8-c,d]-1,2diselenole (2d). According to a method similar to that previously reported for 2a [11-17] from 1,8-dibromo-4nitronaphthalene, $2 \mathbf{d}$ was obtained as dark purple needles in $28 \%$ yield, m.p. $196.0-197.0^{\circ} \mathrm{C} .{ }^{1} \mathrm{H}$ NMR $\left(\mathrm{CDCl}_{3}\right.$, $300 \mathrm{MHz}, \mathrm{TMS}): \delta 7.40(\mathrm{~d}, 1 \mathrm{H}, J=8.3 \mathrm{~Hz}), 7.52(\mathrm{dd}, 1 \mathrm{H}$, $J=4.1$ and $7.6 \mathrm{~Hz}), 7.53(\mathrm{~s}, 1 \mathrm{H}), 8.18(\mathrm{~d}, 1 \mathrm{H}, J=8.3 \mathrm{~Hz})$, $8.51(\mathrm{dd}, 1 \mathrm{H}, J=2.7$ and $4.1 \mathrm{~Hz}) ;{ }^{1} \mathrm{H}$ NMR (DMSO-d $\mathrm{d}_{6}$, $300 \mathrm{MHz}, \mathrm{TMS}): \delta 7.57(\mathrm{dd}, 1 \mathrm{H}, J=7.5$ and $8.5 \mathrm{~Hz}), 7.77$ $(\mathrm{d}, 1 \mathrm{H}, J=8.5 \mathrm{~Hz}), 7.84(\mathrm{dd}, 1 \mathrm{H}, J=0.7$ and $7.5 \mathrm{~Hz}), 8.20$ $(\mathrm{d}, 1 \mathrm{H}, J=8.5 \mathrm{~Hz}), 8.29(\mathrm{dd}, 1 \mathrm{H}, J=0.7$ and $8.5 \mathrm{~Hz}) ;{ }^{13} \mathrm{C}$ NMR (DMSO-d $\mathrm{d}_{6}, 75.5 \mathrm{MHz}, \mathrm{TMS}$ ): $\delta 118.2,120.0,123.4$, $127.1,129.4,131.1,139.0,140.8,144.2,155.5 ;{ }^{77} \mathrm{Se} \mathrm{NMR}$ $\left(\mathrm{CDCl}_{3}, 76.2 \mathrm{MHz}, \mathrm{Me}_{2} \mathrm{Se}\right): \delta 448.8,474.4$. Anal. Calc. for $\mathrm{C}_{10} \mathrm{H}_{5} \mathrm{Se}_{2} \mathrm{NO}_{2}$ : C, 36.50; H, 1.53; N, 4.26\%; found: C, 36.41; $\mathrm{H}, 1.40 ; \mathrm{N}, 4.19 \%$. 


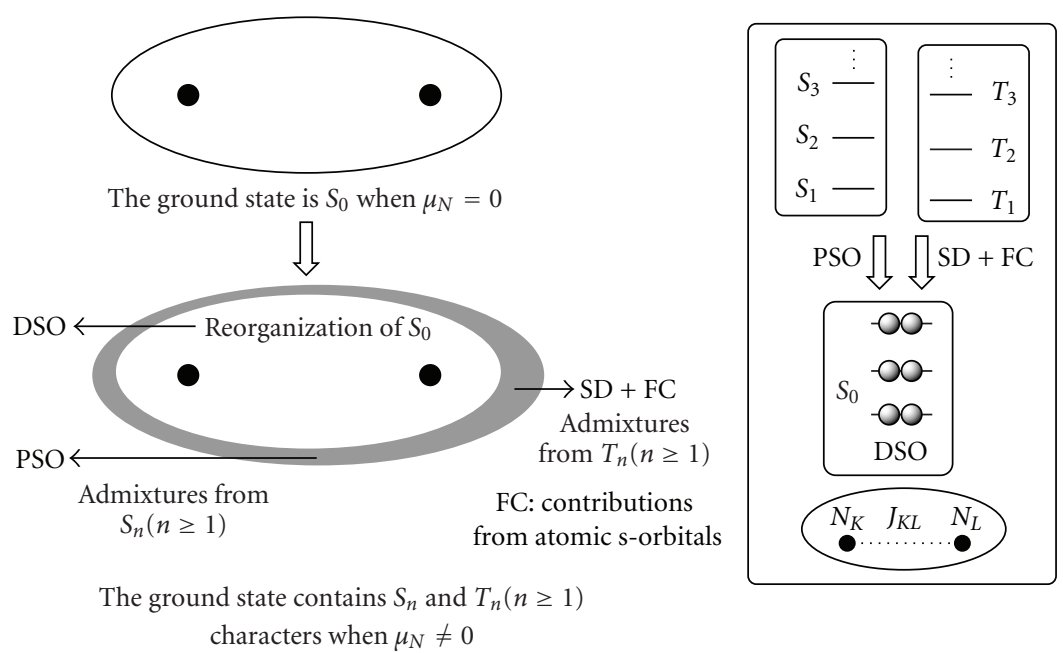

Scheme 1: How do the indirect nuclear spin-spin couplings originate? Mechanisms for ${ }^{n} J_{\mathrm{DSO}},{ }^{n} J_{\mathrm{PSO}},{ }^{n} J_{\mathrm{SD}}$, and ${ }^{n} J_{\mathrm{FC}}$ terms, contributing to ${ }^{n} J_{\mathrm{TL}}$.

TABLE 2: ${ }^{1} J(\mathrm{Se}, \mathrm{Se})$ values calculated for $1 \mathbf{a}^{(\mathrm{a}),(\mathrm{b})}$.

\begin{tabular}{|c|c|c|c|c|c|c|}
\hline $\begin{array}{l}\phi \\
{\left[^{\circ}\right]} \\
\end{array}$ & $\begin{array}{c}E_{\mathrm{rel}}^{(\mathrm{c})} \\
{\left[\mathrm{kJ} \mathrm{mol}^{-1}\right]}\end{array}$ & $\begin{array}{l}{ }^{1} J_{\mathrm{PSO}} \\
{[\mathrm{Hz}]}\end{array}$ & $\begin{array}{l}{ }^{1} J_{\mathrm{SD}} \\
{[\mathrm{Hz}]}\end{array}$ & $\begin{array}{c}{ }^{1} J_{\mathrm{FC}} \\
{[\mathrm{Hz}]}\end{array}$ & $\begin{array}{c}{ }^{1} J_{\mathrm{SD}+\mathrm{FC}} \\
{[\mathrm{Hz}]}\end{array}$ & $\begin{array}{l}{ }^{1} J_{\mathrm{TL}} \\
{[\mathrm{Hz}]}\end{array}$ \\
\hline 0.0 & 36.9 & 447.2 & 217.8 & 18.6 & 236.4 & 683.7 \\
\hline 15.0 & 33.0 & 399.2 & 200.6 & 15.2 & 215.8 & 615.0 \\
\hline 30.0 & 25.3 & 288.5 & 163.1 & 2.7 & 165.8 & 454.3 \\
\hline 60.0 & 6.1 & 76.1 & 101.4 & -43.3 & 58.1 & 134.2 \\
\hline 75.0 & 0.9 & 20.0 & 87.8 & -64.7 & 23.1 & 43.1 \\
\hline 88.4 & 0.0 & 4.1 & 84.5 & -76.7 & 7.8 & 11.9 \\
\hline 90.0 & 0.0 & 4.2 & 84.6 & -77.9 & 6.7 & 10.9 \\
\hline 105.0 & 2.3 & 29.9 & 91.5 & -77.4 & 14.1 & 44.0 \\
\hline 120.0 & 7.4 & 94.7 & 109.3 & -60.5 & 48.8 & 143.5 \\
\hline 150.0 & 17.6 & 291.5 & 171.7 & -8.2 & 163.5 & 455.0 \\
\hline 165.0 & 21.5 & 370.6 & 201.1 & 9.0 & 210.1 & 580.7 \\
\hline 180.0 & 22.8 & 400.7 & 213.4 & 14.3 & 227.7 & 628.4 \\
\hline
\end{tabular}

(a) For the abbreviation, see text.

(b) ${ }^{1} J$ DSO being less than $0.03 \mathrm{~Hz}$.

${ }^{(c)}$ Relative to optimized value $(-5267.7384 \mathrm{au})$ at $\phi=88.38^{\circ}$ in $\mathrm{kJ} \mathrm{mol}^{-1}$.

2.5. Measurements of ${ }^{1} \mathrm{~J}(\mathrm{Se}, \mathrm{Se})$. During the measurement of ${ }^{77} \mathrm{Se}$ NMR spectra for $2 \mathrm{~g}\left(\mathrm{Y}=\mathrm{NO}_{2}\right)$ in chloroform-d solutions $(0.050 \mathrm{M})$ at $297 \mathrm{~K}$, a typical $\mathrm{AB}$ quartet pattern of the spectra was observed. After careful analysis of the spectrum for $2 \mathrm{~g},{ }^{1} J(\mathrm{Se}, \mathrm{Se})$ of $330.8 \mathrm{~Hz}$ was obtained. The ${ }^{1} J(\mathrm{Se}, \mathrm{Se})$ values are obtained similarly by the careful analysis of the spectra for $2 \mathrm{c}$ and $\mathbf{2 d}$.

2.6. Calculation Method. Structures of $\mathbf{1 a}$ are optimized employing the 6-311++G(3df,2pd) basis sets of the Gaussian 03 program [24-28] at the DFT (B3LYP) level [29-32]. The torsional angle $\mathrm{C}_{\mathrm{Me}} \mathrm{SeSeC}_{\mathrm{Me}}(\phi)$ is $88.38^{\circ}$ in the fulloptimized structure of 1a. Calculations that are further performed on 1a: 1a are fully optimized except for $\phi$, which are fixed by every $15^{\circ}$ or $30^{\circ}$. Optimizations are also performed on $\mathbf{2 a - g}$ using the $6-311+\mathrm{G}(3 \mathrm{df})$ basis sets [2528 ] for Se and the $6-311+G(3 d, 2 p)$ basis sets for other nuclei at the DFT (B3LYP) level [29-32]. The $C_{2 v}$ symmetry is assumed for $2 \mathbf{a}, C_{s}$ for $\mathbf{2} \mathbf{b}-\mathbf{d}$ and $\mathbf{2} \mathbf{f}$, and the $C_{1}$ symmetry for $2 \mathrm{e}$ and $2 \mathrm{~g}$.

The $J(\mathrm{Se}, \mathrm{Se})$ values are calculated with the triple $\xi$ basis sets of the Slater type with two sets of polarization functions $(2 \times 1 \mathrm{~s}, 2 \times 2 \mathrm{~s}, 2 \times 2 \mathrm{p}, 2 \times 3 \mathrm{~s}, 2 \times 3 \mathrm{p}, 3 \times 3 \mathrm{~d}, 3 \times 4 \mathrm{~s}$, $3 \times 4 \mathrm{p}, 1 \times 4 \mathrm{~d}$, and $1 \times 4 \mathrm{f}$ for $\mathrm{Se}$ ) at the DFT (BLYP) level of the ADF 2008 program [19-23], applying on the optimized structures with the Gaussian 03 program [24]. Calculations are performed at the nonrelativistic level. The scalar ZORA relativistic formulation [33-35] is also applied to $2 \mathbf{a}$, for convenience of comparison. The ${ }^{n} J_{\mathrm{TL}}$ values are evaluated separately by ${ }^{n} J_{\mathrm{DSO}},{ }^{n} J_{\mathrm{PSO}},{ }^{n} J_{\mathrm{SD}}$, and ${ }^{n} J_{\mathrm{FC}}$, as shown in (1). Mechanisms of the nuclear couplings are revealed by 


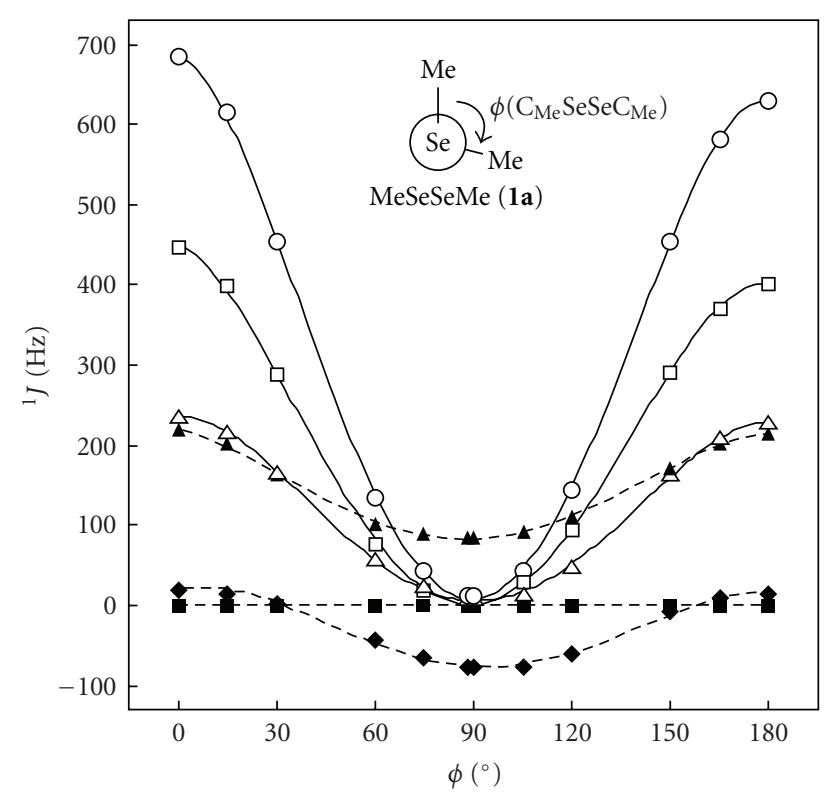

Figure 2: Plots of ${ }^{1} J_{\mathrm{DSO}}(\boldsymbol{\square}),{ }^{1} J_{\mathrm{PSO}}(\square),{ }^{1} J_{\mathrm{SD}}(\boldsymbol{\Delta}),{ }^{1} J_{\mathrm{FC}}(\boldsymbol{\vee}),{ }^{1} J_{\mathrm{SD}+\mathrm{FC}}$ $(\triangle)$, and ${ }^{1} J_{\mathrm{TL}}(\bigcirc)$ versus $\phi(\mathrm{CSeSeC})$ in ${ }^{1} J(\mathrm{Se}$, Se: $\mathbf{1 a})$.

decomposing the contributions to each $\psi_{i}$ and each $\psi_{i} \rightarrow \psi_{a}$ transition $[36,37]$.

\section{Results and Discussion}

3.1. Observed ${ }^{1} J_{\text {obsd }}(\mathrm{Se}, \mathrm{Se})$. Table 1 collects ${ }^{1} J_{\text {obsd }}(\mathrm{Se}, \mathrm{Se})$, necessary for discussion. The magnitudes of the ${ }^{1} J_{\text {obsd }}(\mathrm{Se}$, $\mathrm{Se})$ values are usually small $(<64 \mathrm{~Hz})$ for the simple derivatives of MeSeSeMe (1a) (RSeSeR': 1) [9, 16, 17]. On the other hand, large ${ }^{1} J_{\text {obsd }}(\mathrm{Se}, \mathrm{Se})$ are recorded for 2 (4-Y-1,8$\mathrm{Se}_{2} \mathrm{C}_{10} \mathrm{H}_{5}$ ), which correspond to symperiplanar diselenides, although not detected in $2 \mathbf{a}(\mathrm{Y}=\mathrm{H})$ [11-15]. The values are $379.4 \mathrm{~Hz}$ for $\mathbf{2 b}(\mathrm{Y}=\mathrm{Me}), 375.9 \mathrm{~Hz}$ for $2 \mathbf{c}(\mathrm{Y}=\mathrm{Cl})$, and $330.8 \mathrm{~Hz}$ for $\mathbf{2 d}\left(\mathrm{Y}=\mathrm{NO}_{2}\right) .{ }^{1} J$ (Se, Se: 2$)$ becomes smaller as the electron accepting ability of $\mathrm{Y}$ increases.

3.2. Mechanism of ${ }^{1} \mathrm{~J}(\mathrm{Se}, \mathrm{Se})$ in 1a. Table 2 shows the calculated ${ }^{1} J_{\mathrm{TL}}$ and the components, ${ }^{1} J_{\mathrm{DSO}},{ }^{1} J_{\mathrm{PSO}},{ }^{1} J_{\mathrm{SD}}$, and ${ }^{1} J_{\mathrm{FC}}$, in ${ }^{1} J$ (Se, Se: 1a). ${ }^{1} J_{\mathrm{TL}}$ (Se, Se: 1a) is predicted to be less than $44 \mathrm{~Hz}$ for $\phi=90^{\circ} \pm 15^{\circ}$. Therefore, ${ }^{1} J_{\text {obsd }}$ (Se, Se: 1 ) is explained substantially and modeled by 1 a with $\phi \approx 90^{\circ}$, although $\mathrm{R}$ and $\mathrm{R}^{\prime}$ in $\mathbf{1}$ must also affect on the values. ${ }^{1} J$ (Se, Se: 1a) is predicted to be very large at $\phi=0^{\circ}(684 \mathrm{~Hz})$ and $180^{\circ}(628 \mathrm{~Hz})$. Consequently, ${ }^{1} J_{\text {obsd }}($ Se, Se: 2$)$ of $331-379 \mathrm{~Hz}$ are essentially explained by ${ }^{1} J(\mathrm{Se}, \mathrm{Se}: \mathbf{1 a})$ with $\phi=0^{\circ}$. Figure 2 draws the plots of ${ }^{1} J_{\mathrm{DSO}},{ }^{1} J_{\mathrm{PSO}},{ }^{1} J_{\mathrm{SD}},{ }^{1} J_{\mathrm{FC}},{ }^{1} J_{\mathrm{SD}}+\mathrm{FC}$, and ${ }^{1} J_{\mathrm{TL}}$ versus $\phi$ in 1a. It is well demonstrated that ${ }^{1} J_{\mathrm{TL}}$ changes depending on $\phi$, similarly to the case of ${ }^{3} J(\mathrm{H}, \mathrm{H})$, three-bond (vicinal) couplings in ${ }^{1} \mathrm{H}$ NMR spectra $[1,2]$. ${ }^{1} J_{\text {DSO }}$ are negligible $(<0.03 \mathrm{~Hz})$.

How do ${ }^{1} J_{\mathrm{PSO}}(\mathrm{Se}, \mathrm{Se}: \mathbf{1 a})$ and ${ }^{1} J_{\mathrm{SD}+\mathrm{FC}}(\mathrm{Se}$, Se: 1a) $\left[={ }^{1} J_{\mathrm{SD}}(\mathrm{Se}, \mathrm{Se}: \mathbf{1 a})+{ }^{1} J_{\mathrm{FC}}(\mathrm{Se}, \mathrm{Se}: \mathbf{1 a})\right]$ contribute to ${ }^{1} J_{\mathrm{TL}}(\mathrm{Se}$, Se: 1a)? ${ }^{1} J_{\mathrm{PSO}}(\mathrm{Se}, \mathrm{Se}: \mathbf{1 a})$ and ${ }^{1} J_{\mathrm{SD}+\mathrm{FC}}(\mathrm{Se}, \mathrm{Se}: \mathbf{1 a})$ are plotted versus ${ }^{1} J_{\mathrm{TL}}(\mathrm{Se}, \mathrm{Se}: \mathbf{1 a})$, although not shown. The correlations are given in (2) and (3), respectively. The results exhibit that ${ }^{1} J_{\mathrm{PSO}}(\mathrm{Se}, \mathrm{Se}: 1 \mathbf{1 a})$ and ${ }^{1} J_{\mathrm{SD}+\mathrm{FC}}(\mathrm{Se}, \mathrm{Se}$ : 1a) contribute $65 \%$ and $35 \%$ to ${ }^{1} J_{\mathrm{TL}}$ (Se, Se: 1a), respectively, irrespective of the $\phi(\mathrm{CSeSeC})$ values:

$$
\begin{aligned}
& { }^{1} J_{\mathrm{PSO}}(\text { Se, Se: } 1 \mathbf{a}) \\
& \quad=0.651 \times{ }^{1} J_{\mathrm{TL}}(\text { Se, Se: } 1 \mathbf{a})-4.1\left(r^{2}=0.999\right), \\
& { }^{1} J_{\mathrm{SD}+\mathrm{FC}}(\text { Se, Se: } 1 \mathbf{a}) \\
& \quad=0.349 \times{ }^{1} J_{\mathrm{TL}}(\text { Se, Se: } \mathbf{1 a})+4.2\left(r^{2}=0.998\right) .
\end{aligned}
$$

Why does ${ }^{1} J($ Se, Se: 1a) show the torsional angular dependence? What orbitals and transitions contribute to the dependence? ${ }^{1} J_{\text {PSO }}$ (Se, Se: 1a) is analyzed next.

3.2.1. Analysis of ${ }^{1} J_{P S O}(\mathrm{Se}, \mathrm{Se})$ in 1a. The mechanism of ${ }^{1} J_{\text {PSO }}$ (Se, Se: 1a) is discussed by analyzing the contributions separately from each $\psi_{i}$ and each $\psi_{i} \rightarrow \psi_{a}$ transition. Table 3 lists the $\phi$ dependence of ${ }^{1} J_{\mathrm{PSO}}$ (Se, Se: 1a) contributed from $\psi_{1}-\psi_{43}, \psi_{1}-\psi_{38}, \psi_{39}-\psi_{43}, \psi_{39}, \psi_{40}, \psi_{41}, \psi_{42}$, and $\psi_{43}$. The contribution from $\psi_{39}-\psi_{43}$ to ${ }^{1} J_{\mathrm{PSO}}(\mathrm{Se}, \mathrm{Se}$ : 1a) is large, whereas that from $\psi_{1}-\psi_{38}$ is small, although not shown. The plot of the contributions from $\psi_{39}-\psi_{43}(y)$ versus those from $\psi_{1}-\psi_{43}(x)$ provides an excellent correlation $(y=0.976 x+$ $\left.37.3: r^{2}=0.9999\right)$. Figure 3(a) shows those from $\psi_{39}, \psi_{40}$, $\psi_{41}, \psi_{42}$, and $\psi_{43}$ and Figure $3(\mathrm{~b})$ exhibits those from $\psi_{39}-$ $\psi_{41}, \psi_{42}-\psi_{43}$, and $\psi_{39}-\psi_{43}$. Contributions from $\psi_{42}$ and $\psi_{43}$ exchange with each other at $\phi \approx 90^{\circ}$. Those of $\psi_{39}$ and $\psi_{40}$ do at $\phi \approx 135^{\circ}$ (Figure 3(a)). The contributions from $\psi_{42}-\psi_{43}$ and $\psi_{39}-\psi_{41}$ almost cancel out at $\phi \approx 90^{\circ}$ (Figure 3(b)).

Magnitudes of the contributions from $\psi_{42}$ and $\psi_{43}$ to ${ }^{1} J_{\text {PSO }}$ (Se, Se: 1a) are very large at $0^{\circ}$ and $180^{\circ}$ (Table 3), although those from $\psi_{42}$ and $\psi_{43}$ are negative and positive directions, respectively. The values amount to -353 to $-360 \mathrm{~Hz}$ and $753-793 \mathrm{~Hz}$, respectively. The contributions from $\psi_{42}-\psi_{43}$ are 433,218 , and $400 \mathrm{~Hz}$ at $0^{\circ}, 90^{\circ}$, and $180^{\circ}$, respectively, and those from $\psi_{39}-\psi_{41}$ are $17,-198$, and $10 \mathrm{~Hz}$ at $0^{\circ}, 90^{\circ}$, and $180^{\circ}$, respectively. Therefore, the mechanism of ${ }^{1} J_{\mathrm{PSO}}(\mathrm{Se}$, Se: 1a) will be clarified by analyzing the contributions from $\psi_{42}$ and $\psi_{43}$ at $0^{\circ}$ and $180^{\circ}$. The mechanism would be complex at $90^{\circ}$, since the small magnitude is the results of the total contributions from $\psi_{39}-\psi_{43}$.

Figure 4 shows the $\psi_{42} \rightarrow \psi_{44}$ and $\psi_{43} \rightarrow \psi_{44}$ transitions at both $\phi=0^{\circ}$ and $180^{\circ}$ which are shown in Table 3. Characters of $\psi_{42}(\mathrm{HOMO}-1), \psi_{43}(\mathrm{HOMO})$, and $\psi_{44}$ (LUMO) are $\pi(\mathrm{Se}-\mathrm{Se}), \pi^{*}(\mathrm{Se}-\mathrm{Se})$, and $\sigma^{*}(\mathrm{Se}-\mathrm{Se})$, respectively, at $\phi=0^{\circ}$ and $180^{\circ} \cdot \psi_{42}(\mathrm{HOMO}-1)$ is essentially the same as $\psi_{43}(\mathrm{HOMO})$ at $\phi=90^{\circ} . \psi_{42}$ and $\psi_{43}$ at $\phi=90^{\circ}$ are also drawn in Figure 4 , to show how $\psi_{42}$ and $\psi_{43}$ interconvert with each other. Contrary to the case of $\phi \approx 0$ and $180^{\circ}$, all of $\psi_{39}-$ $\psi_{43}$ contribute to ${ }^{1} J_{\mathrm{PSO}}(\mathrm{Se}, \mathrm{Se}: 1 \mathrm{1a})$ at $\phi \approx 90^{\circ}$. Contributions from the $\psi_{42} \rightarrow \psi_{44}$ and $\psi_{43} \rightarrow \psi_{44}$ transitions to ${ }^{1} J_{\mathrm{PSO}}(\mathrm{Se}$, Se: 1a) at $90^{\circ}$ are almost cancelled by those from the $\psi_{39} \rightarrow$ $\psi_{44}, \psi_{40} \rightarrow \psi_{44}$, and $\psi_{41} \rightarrow \psi_{44}$ transitions. In addition, both ${ }^{1} J_{\mathrm{SD}}(\mathrm{Se}, \mathrm{Se}: \mathbf{1 a})$ and ${ }^{1} J_{\mathrm{FC}}(\mathrm{Se}, \mathrm{Se}: \mathbf{1 a})$ substantially contribute at $\phi \approx 90^{\circ}$. Consequently, it is difficult to specify a few 
TABle 3: Contributions to the torsional angular dependence in ${ }^{1} J_{\mathrm{PSO}}\left(\mathrm{Se}, \mathrm{Se}\right.$ : 1a) from $\psi_{i}{ }^{(\mathrm{a}),(\mathrm{b})}$.

\begin{tabular}{lcccccccccccc}
\hline$\phi\left[^{\circ}\right]$ & 0.0 & 15.0 & 30.0 & 60.0 & 75.0 & 88.4 & 90.0 & 105.0 & 120.0 & 150.0 & 165.0 & 180.0 \\
\hline$\psi_{1}-\psi_{43}$ & 447.2 & 399.2 & 288.5 & 76.1 & 19.9 & 4.1 & 4.3 & 29.9 & 94.7 & 291.4 & 370.5 & 400.7 \\
$\psi_{39}-\psi_{43}$ & 449.9 & 403.1 & 294.9 & 84.4 & 35.2 & 20.4 & 20.6 & 45.9 & 109.1 & 302.2 & 380.3 & 410.4 \\
$\psi_{39}$ & -121.2 & -117.6 & -108.9 & -80.9 & -63.0 & -44.9 & -42.6 & -18.9 & 8.7 & -146.9 & -155.1 & -157.7 \\
$\psi_{40}$ & 181.2 & 163.4 & 118.7 & 13.7 & -28.6 & -59.4 & -62.8 & -90.8 & -114.3 & 65.3 & 85.4 & 93.0 \\
$\psi_{41}$ & -43.3 & -48.3 & -60.8 & -87.9 & -94.3 & -93.1 & -92.4 & -79.9 & -54.0 & 28.7 & 62.4 & 75.0 \\
$\psi_{42}$ & -359.7 & -333.7 & -266.1 & -84.0 & 9.6 & 95.6 & 111.9 & 21.2 & -71.9 & -261.5 & -328.1 & -352.7 \\
$\psi_{43}$ & 792.9 & 739.4 & 612.0 & 323.7 & 211.5 & 122.2 & 106.5 & 214.3 & 340.7 & 616.6 & 715.7 & 752.8 \\
$\psi_{42} \rightarrow \psi_{44}{ }^{(\mathrm{c})}$ & -333.3 & -307.1 & -240.9 & -69.4 & 15.6 & 93.3 & 116.5 & 33.2 & -54.4 & -235.6 & -298.1 & -321.0 \\
$\psi_{43} \rightarrow \psi_{44}{ }^{(\mathrm{c})}$ & 747.2 & 695.7 & 574.7 & 312.4 & 206.8 & 125.9 & 103.2 & 202.0 & 320.7 & 581.5 & 673.8 & 708.6 \\
\hline
\end{tabular}

${ }^{(a)}$ In $\mathrm{Hz}$.

(b) For the abbreviation, see text.

${ }^{\text {(c) }}$ Contribution from the transition.

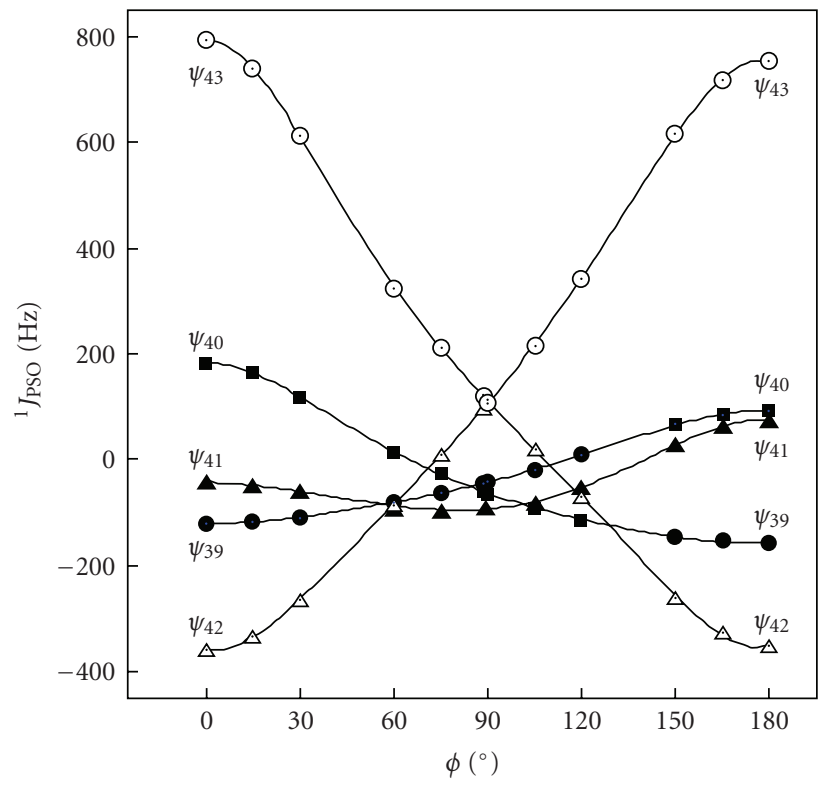

(a)

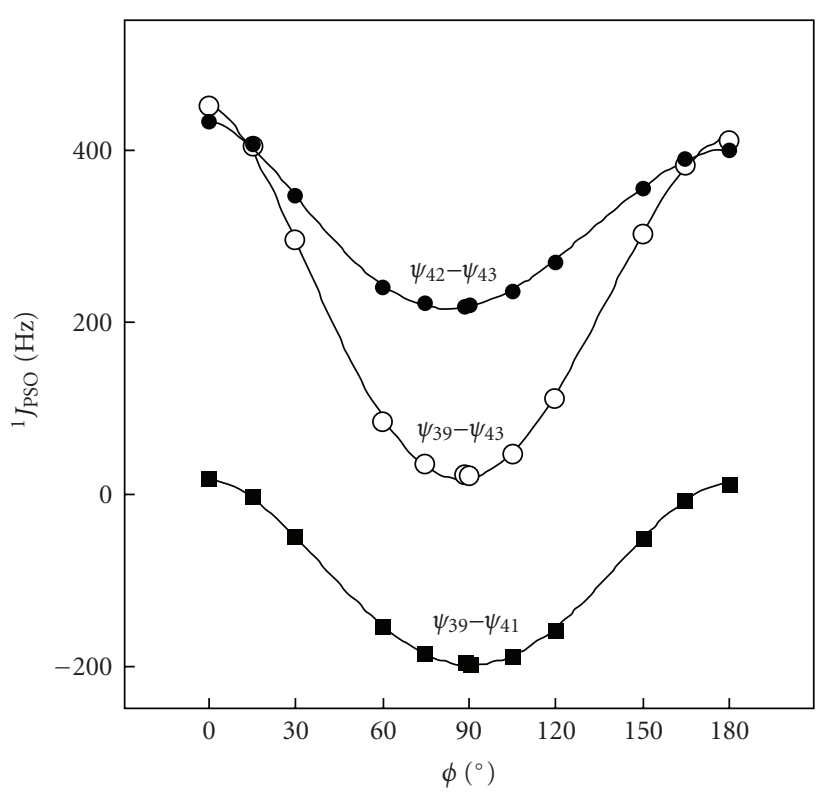

(b)

FIGURE 3: Origin of the torsional angular dependence in ${ }^{1} J_{\text {PSO }}$ (Se, Se: 1a): (a) contributions from each of $\psi_{39}, \psi_{40}, \psi_{41}, \psi_{42}$, and $\psi_{43}$ and (b) those from $\psi_{39}-\psi_{41}, \psi_{42}-\psi_{43}$, and $\psi_{39}-\psi_{43}$.

orbitals, together with the transitions, which control ${ }^{1} J$ (Se, Se: 1 a) at $\phi \approx 90^{\circ}$. The character of $\psi_{44}$ [LUMO: $\sigma^{*}(\mathrm{Se}-$ Se)] does not change so much depending on $\phi$. Therefore, the behavior of $\psi_{39}-\psi_{43}$ must be mainly responsible for the $\phi$ dependence in ${ }^{1} J$ (Se, Se: 1a) (see Figures 3 and 4). The MO description in Figure 4 visualizes the origin of ${ }^{1} J_{\mathrm{PSO}}$ (Se, Se: 1a) and helps us to understand the mechanism, especially at $\phi=0^{\circ}$ and $180^{\circ}$.

After elucidation of the mechanism for ${ }^{1} J_{\mathrm{PSO}}$ (Se, Se: 1a), next extension is to clarify ${ }^{1} J$ (Se, Se: 2 ) on the basis of the MO theory.

3.2.2. Evaluation of ${ }^{1} J(\mathrm{Se}, \mathrm{Se})$ for 2 . Table 4 collects the calculated ${ }^{1} J_{\mathrm{TL}}(\mathrm{Se}, \mathrm{Se}: 2)$ values, together with $J_{\mathrm{PSO}}(\mathrm{Se}, \mathrm{Se}$ : 2), ${ }^{1} J_{\mathrm{SD}}$ (Se, Se: 2$),{ }^{1} J_{\mathrm{FC}}(\mathrm{Se}, \mathrm{Se}: 2)$, and ${ }^{1} J_{\mathrm{SD}+\mathrm{FC}}(\mathrm{Se}, \mathrm{Se}: 2)$. Table 4 also contains the nuclear changes calculated with the natural bond orbital analysis (NBO) method $(\mathrm{Q} n(\mathrm{Se}))$ [38-40] for 2 having $\mathrm{Y}$ of $\mathrm{H}(\mathbf{a}), \mathrm{OMe}(\mathbf{b}), \mathrm{Me}(\mathbf{c}), \mathrm{Cl}$ (d), COOMe (e), $\mathrm{CN}(\mathbf{f})$, and $\mathrm{NO}_{2}(\mathbf{g})$. The Y dependence of ${ }^{1} J_{\text {obsd }}$ (Se, Se: 2 ) is well reproduced by the calculations. ${ }^{1} J_{\mathrm{TL}}$ (Se, Se: 2 ) are predicted to be larger than the observed values by about $100 \mathrm{~Hz}$. The DFT method overestimates the reciprocal energy differences $\left(\varepsilon_{a}-\varepsilon_{i}\right)^{-1}$, which would partly be responsible for the larger evaluation. The ${ }^{1} J$ (Se, Se) values are calculated at both nonrelativistic and scalar ZORA relativistic levels for $\mathbf{2 a}$. The former is smaller than the latter. The value calculated at the nonrelativistic level seems to be closer to the observed value than that obtained with the scalar ZORA relativistic formulation in our calculation system. Therefore, it would be reasonable to discuss the ${ }^{n} J$ (Se, Se) value calculated at the nonrelativistic level in this case. 


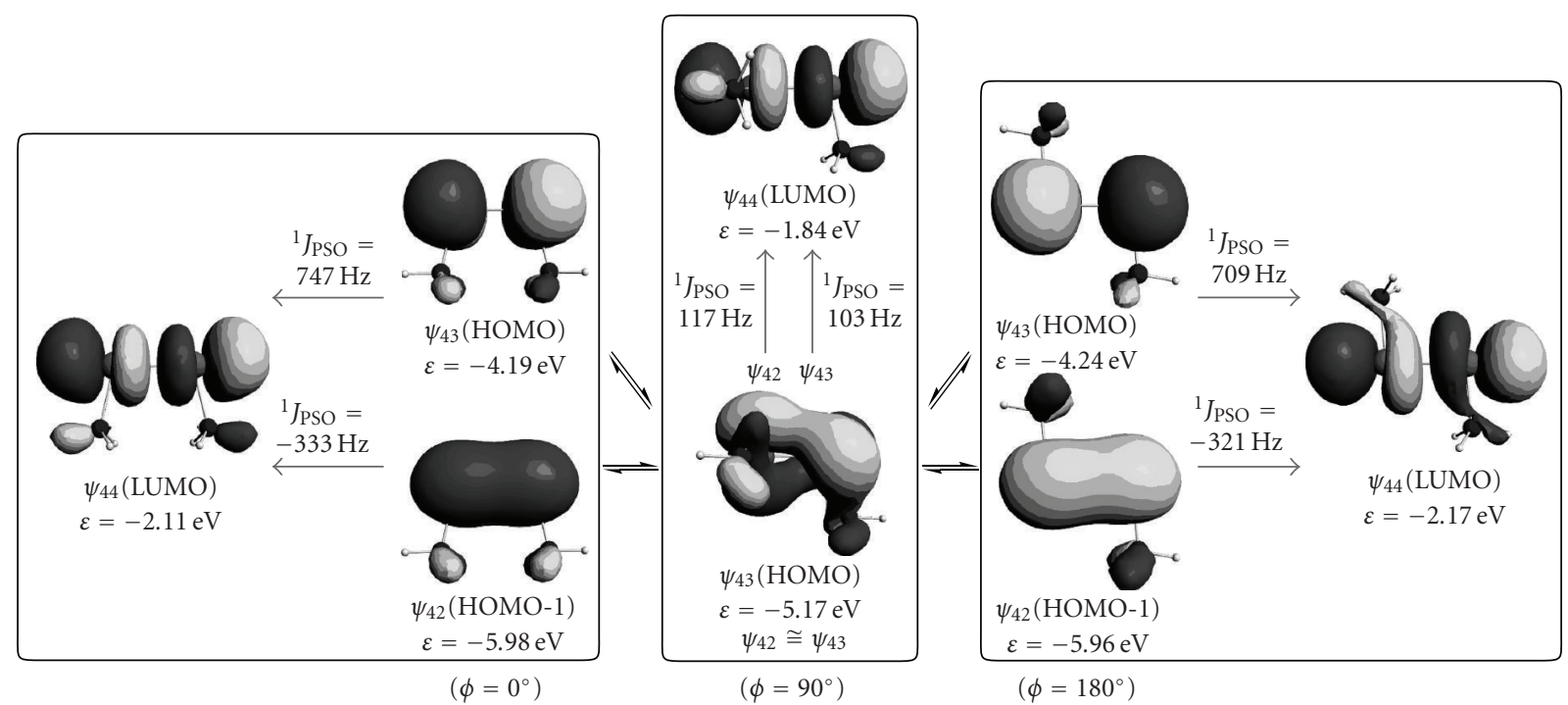

Figure 4: Contributions to ${ }^{1} J_{\mathrm{PSO}}(\mathrm{Se}, \mathrm{Se}: 1 \mathrm{1a})$ from the $\psi_{42} \rightarrow \psi_{44}$ and $\psi_{43} \rightarrow \psi_{44}$ transitions at $\phi=0$, 90, and $180^{\circ}$. The interconversion between $\psi_{42}$ and $\psi_{43}$ at $\phi \approx 90^{\circ}$ is also depicted.

TABLe 4: ${ }^{1} J(\mathrm{Se}, \mathrm{Se})$ and $\mathrm{Q} n(\mathrm{Se})$ calculated on the full-optimized structure of $\mathbf{2}^{(\mathrm{a}),(\mathrm{b}),(\mathrm{c})}$.

\begin{tabular}{|c|c|c|c|c|c|c|c|c|}
\hline Compound & ${ }^{1} J_{\mathrm{PSO}}[\mathrm{Hz}]$ & ${ }^{1} J_{\mathrm{SD}}[\mathrm{Hz}]$ & ${ }^{1} J_{\mathrm{FC}}[\mathrm{Hz}]$ & ${ }^{1} J_{\mathrm{SD}+\mathrm{FC}}[\mathrm{Hz}]$ & ${ }^{1} J_{\mathrm{TL}}[\mathrm{Hz}]$ & $Q n\left({ }^{1} \mathrm{Se}\right)$ & $Q n\left({ }^{2} \mathrm{Se}\right)$ & Symmetry \\
\hline $2 \mathbf{a}(\mathrm{Y}=\mathrm{H})$ & 362.2 & 195.2 & -54.1 & 141.1 & 503.3 & 0.2367 & 0.2367 & $C_{2 v}$ \\
\hline $2 \mathbf{b}(\mathrm{Y}=\mathrm{OMe})$ & 394.3 & 207.5 & -54.2 & 153.3 & 547.7 & 0.2256 & 0.2264 & $C_{s}$ \\
\hline $2 c(Y=M e)$ & 363.6 & 195.1 & -55.3 & 139.8 & 503.5 & 0.2334 & 0.2296 & $C_{s}$ \\
\hline $2 \mathbf{d}(\mathrm{Y}=\mathrm{Cl})$ & 360.1 & 193.4 & -53.1 & 140.3 & 500.4 & 0.2448 & 0.2443 & $C_{s}$ \\
\hline $2 \mathbf{e}(\mathrm{Y}=\mathrm{COOMe})$ & 324.1 & 178.2 & -55.7 & 122.5 & 446.6 & 0.2593 & 0.2556 & $C_{1}$ \\
\hline $\mathbf{2} \mathbf{f}(\mathrm{Y}=\mathrm{CN})$ & 326.6 & 180.6 & -52.6 & 128.0 & 454.6 & 0.2677 & 0.2564 & $C_{s}$ \\
\hline $\mathbf{2} \mathbf{g}\left(\mathrm{Y}=\mathrm{NO}_{2}\right)$ & 299.7 & 167.6 & -53.9 & 113.7 & 413.4 & 0.2824 & 0.2576 & $C_{1}$ \\
\hline $2 \mathbf{a}(\mathrm{Y}=\mathrm{H})^{(\mathrm{d})}$ & 390.7 & 206.4 & 2.6 & 209.0 & 599.7 & 0.2367 & 0.2367 & $C_{2 v}$ \\
\hline
\end{tabular}

${ }^{(a)}$ For the abbreviation, see text.

(b) ${ }^{1} J_{\text {DSO }}$ being less than $0.03 \mathrm{~Hz}$.

(c) ${ }^{1} \mathrm{Se}$ and ${ }^{2} \mathrm{Se}$ being attached to ${ }^{1} \mathrm{C}$ and ${ }^{8} \mathrm{C}$ in $4-\mathrm{Y}-1,8-\mathrm{Se}_{2} \mathrm{C}_{10} \mathrm{H}_{5}$ (2), respectively.

(d) On the basis of scalar ZORA.

Before discussion of ${ }^{1} J$ (Se, Se: 2 ), it would be instructive to clarify the behavior of $\mathrm{Qn}$ (Se: 2), which changes depending on Y. Figure 5 shows the plot of $Q n\left({ }^{2} \mathrm{Se}: 2\right)$ versus $\mathrm{Qn}\left({ }^{1} \mathrm{Se}: 2\right)$. The correlations of the linear type $(y=a x+b$ with $r$ (correlation coefficient)) are given in the figure. The results show that $Q n\left({ }^{2} \mathrm{Se}: 2\right)$ grows larger as the accepting ability of $\mathrm{Y}$ increases for $\mathrm{Y}=\mathrm{H}, \mathrm{OMe}, \mathrm{Me}, \mathrm{Cl}$, and COOMe then it becomes almost constant for $\mathrm{Y}=\mathrm{CN}$ and $\mathrm{NO}_{2}$ while $\mathrm{Q} n\left({ }^{1} \mathrm{Se}: 2\right)$ grows larger as the accepting ability of $\mathrm{Y}$ increases for all Y in Table 4. $Q n\left({ }^{2} \mathrm{Se}: 2\right)$ seems saturated for Y of very strong acceptors such as $\mathrm{CN}$ and $\mathrm{NO}_{2}$ while $\mathrm{Q} n\left({ }^{1} \mathrm{Se}: 2\right)$ will not for all Y.

How do ${ }^{1} J_{T L}(\mathrm{Se}$, Se: 2$)$ being controlled? ${ }^{1} J_{T L}$ (Se, Se: 2) are plotted versus $Q n\left({ }^{1} \mathrm{Se}\right), \quad \mathrm{Q} n\left({ }^{2} \mathrm{Se}\right)$, and $\mathrm{Q} n\left({ }^{1} \mathrm{Se}\right)+\mathrm{Q} n\left({ }^{2} \mathrm{Se}\right)$. Figure 6 shows the plot of ${ }^{1} J_{T L}(\mathrm{Se}$, Se: 2$)$ versus $Q n\left({ }^{1} \mathrm{Se}\right)$, which gives best correlation among the three. The correlation is given in the figure. ${ }^{1} J_{T L}(\mathrm{Se}$, Se: 2) are confirmed to be controlled by $\mathrm{Q} n\left({ }^{1} \mathrm{Se}\right)$. One might imagine that ${ }^{1} J_{\mathrm{TL}}$ (Se, Se: 2 ) should be controlled by $\mathrm{Q} n\left({ }^{1} \mathrm{Se}\right)+\mathrm{Q} n\left({ }^{2} \mathrm{Se}\right)$. The saturation in $\mathrm{Qn}\left({ }^{2} \mathrm{Se}\right)$ shown in
Figure 5 would perturb to give good correlations for ${ }^{1} J_{\mathrm{TL}}(\mathrm{Se}$, Se: 2) versus $Q n\left({ }^{1} \mathrm{Se}\right)+Q n\left({ }^{2} \mathrm{Se}\right)$. It is demonstrated that ${ }^{1} J_{\mathrm{TL}}$ (Se, Se: 2) becomes smaller when $\mathrm{Q} n(\mathrm{Se})$ increases, experimentally and theoretically.

After clarification of the Y dependence in ${ }^{1} J_{\mathrm{TL}}$ (Se, Se: 2), next extension is to elucidate the mechanism for ${ }^{1} J$ (Se, Se: 2) on the basis of the MO theory.

3.3. Mechanism of ${ }^{1} J(S e, S e)$ in 2a. How do ${ }^{1} J_{\mathrm{PSO}}$ (Se, Se: 2) and ${ }^{1} J_{\mathrm{SD}+\mathrm{FC}}(\mathrm{Se}, \mathrm{Se}: 2)$ contribute to ${ }^{1} J_{\mathrm{TL}}(\mathrm{Se}, \mathrm{Se}: 2)$ in the change of Y? ${ }^{1} J_{\mathrm{PSO}}$ (Se, Se: 2 ) and ${ }^{1} J_{\mathrm{SD}+\mathrm{FC}}$ (Se, Se: 2 ) are plotted versus ${ }^{1} J_{\mathrm{TL}}$ (Se, Se: 2) for various $\mathrm{Y}$ in Table 4 . The results for ${ }^{1} J_{\mathrm{PSO}}$ (Se, Se: 2 ) and ${ }^{1} J_{\mathrm{SD}+\mathrm{FC}}(\mathrm{Se}, \mathrm{Se}: 2)$ are given in (4) and (5), respectively. The correlations are very good, which shows that ${ }^{1} J_{\mathrm{PSO}}$ (Se, Se: 2 ) contributes predominantly to ${ }^{1} J_{\mathrm{TL}}$ (Se, Se: 2$)(70 \%)$, irrespective of Y:

${ }^{1} J_{\mathrm{PSO}}(\mathrm{Se}, \mathrm{Se}: 2)$

$$
=0.704 \times{ }^{1} J_{\mathrm{TL}}(\text { Se, Se : } 2)+8.3\left(r^{2}=0.999\right),
$$




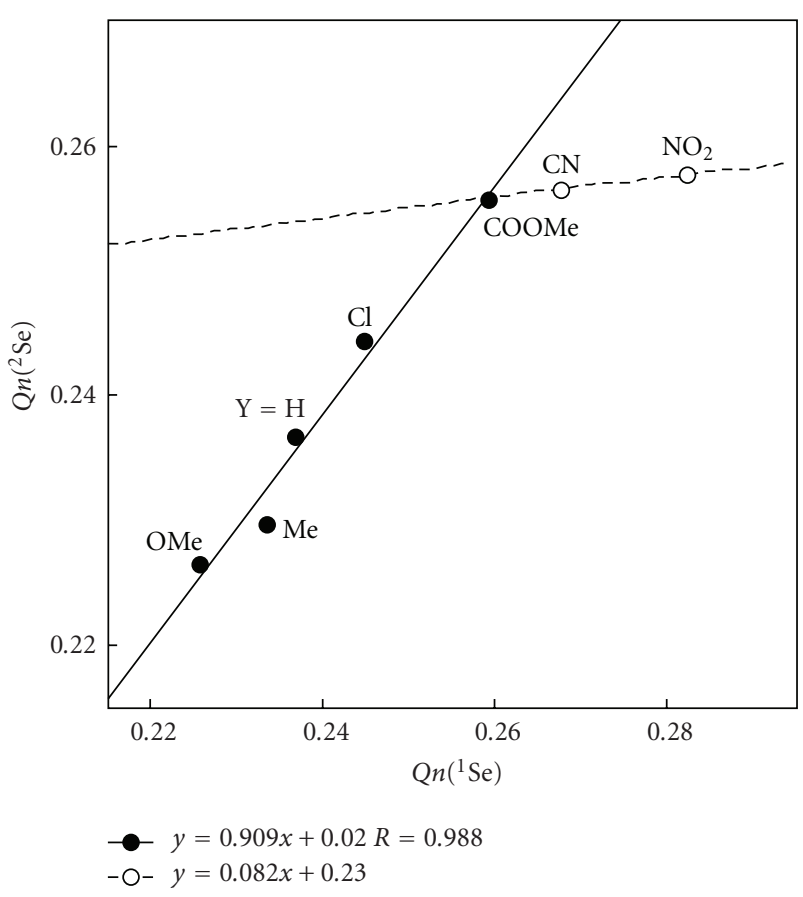

Figure 5: Plot of $Q n\left({ }^{2} \mathrm{Se}\right)$ versus $Q n\left({ }^{1} \mathrm{Se}\right)$ in 2.

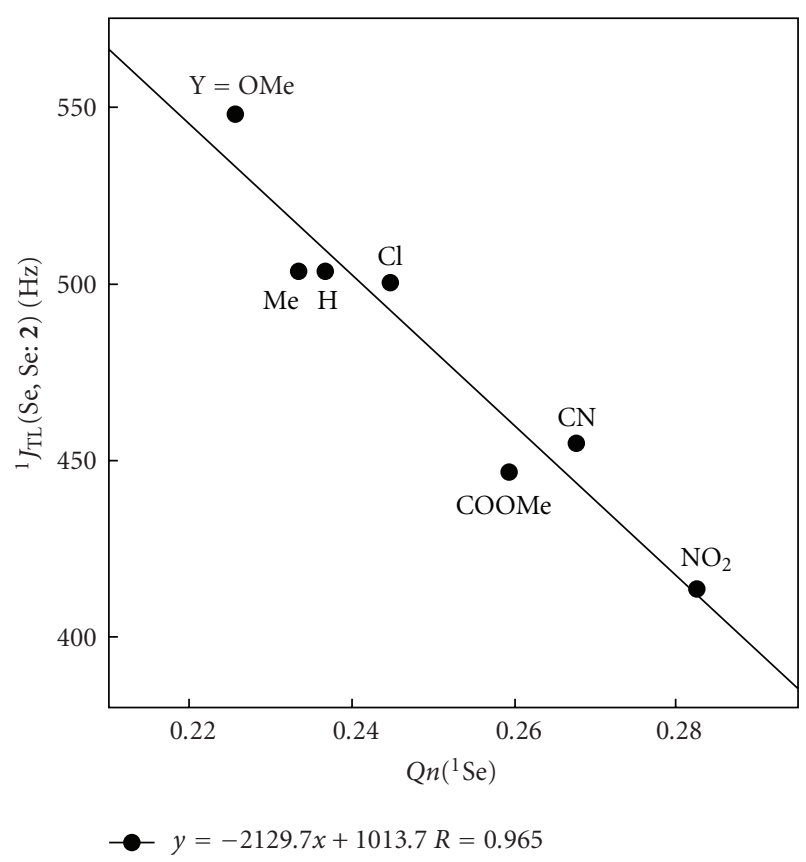

Figure 6: Plot of ${ }^{1} J(\mathrm{Se}, \mathrm{Se}: 2)$ versus $Q n\left({ }^{1} \mathrm{Se}\right)$ in 2.

${ }^{1} J_{\mathrm{SD}+\mathrm{FC}}(\mathrm{Se}, \mathrm{Se}: \mathbf{2})$

$$
=0.295 \times{ }^{1} J_{\mathrm{TL}}(\text { Se, Se : } 2)-8.0\left(r^{2}=0.994\right)
$$

The origin of ${ }^{1} J$ (Se, Se: 2 ) is elucidated by analyzing ${ }^{1} J_{\mathrm{PSO}}(\mathrm{Se}$, Se: $2 \mathrm{a})$ on the basis of the MO theory, since ${ }^{1} J_{\mathrm{PSO}}(\mathrm{Se}, \mathrm{Se})$ contributes predominantly to ${ }^{1} J_{\mathrm{TL}}(\mathrm{Se}, \mathrm{Se})$

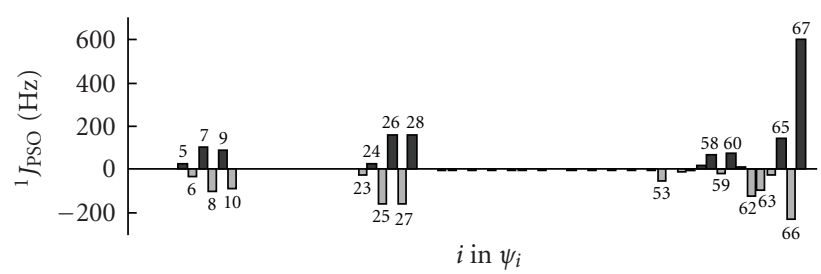

(a)

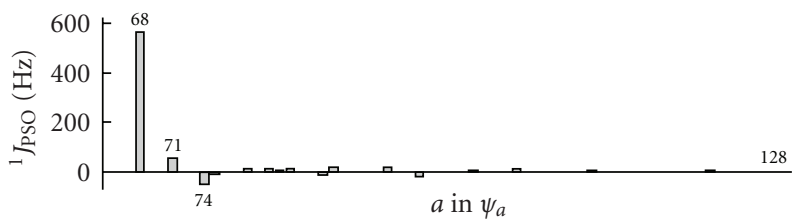

(b)

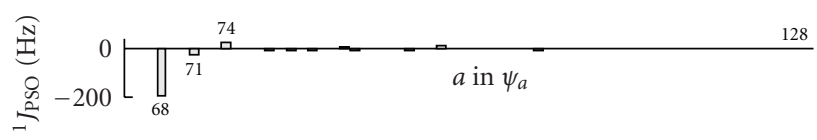

(c)

FIGURE 7: MO analysis of ${ }^{1} J_{\text {PSO }}$ (Se, Se: $2 a$ ): (a) contributions from each $\psi_{i}$, (b) from each $\psi_{67} \rightarrow \psi_{a}$ transition, and (c) from each $\psi_{66} \rightarrow \psi_{a}$ transition.

irrespective of Y. Figure 7 depicts the contributions of ${ }^{1} J_{\mathrm{PSO}}$ (Se, Se: 2a) separately from each $\psi_{i}$ and each $\psi_{i} \rightarrow$ $\psi_{a}$ transition. (a) $-(\mathrm{c})$ in Figure 7 plot the contributions to ${ }^{1} J_{\text {PSO }}($ Se, Se: $2 a)$ from each $\psi_{i}$ and each transition of the $\psi_{67} \rightarrow \psi_{a}$ and $\psi_{66} \rightarrow \psi_{a}$ types, respectively. In Figure 7(a), contributions around $\psi_{5}-\psi_{10}, \psi_{23}-\psi_{28}$, and $\psi_{53}-\psi_{67}$ originate mainly from atomic $2 \mathrm{p}(\mathrm{Se}), 3 \mathrm{p}(\mathrm{Se})$, and $4 \mathrm{p}(\mathrm{Se})$ orbitals, respectively. Those caused by $2 \mathrm{p}(\mathrm{Se})$ and $3 \mathrm{p}(\mathrm{Se})$ are almost cancelled by summarizing over the corresponding orbitals. Therefore, $4 \mathrm{p}(\mathrm{Se})$ substantially contribute to ${ }^{1} J_{\mathrm{PSO}}$ (Se, Se: 2a). Especially, $\psi_{67}$ (HOMO) and $\psi_{66}$ (HOMO-1) control ${ }^{1} J_{\text {PSO }}($ Se, Se: $2 \mathbf{a}) \cdot \psi_{a}$ of $\psi_{68}$ determines ${ }^{1} J_{\text {PSO }}($ Se, Se: $2 \mathbf{a}$ ), among a lot of $\psi_{i} \rightarrow \psi_{a}$ transitions in $\psi_{i}$ of $\psi_{67}$ and $\psi_{66}$, as shown in Figures 7(b) and 7(c).

Figure 8 shows the $\psi_{67} \rightarrow \psi_{68}$ and $\psi_{66} \rightarrow \psi_{68}$ transitions in ${ }^{1} J_{\mathrm{PSO}}(\mathrm{Se}, \mathrm{Se}: 2 \mathbf{2 a})$. The large ${ }^{1} J_{\mathrm{PSO}}(\mathrm{Se}, \mathrm{Se}$ : 2a) value arises from the mixing of $\psi_{68}$ [LUMO: $\left.\sigma^{*}(\mathrm{Se}-\mathrm{Se})\right]$ into $\psi_{67}$ [HOMO: $\left.\pi^{*}(\mathrm{Se}-\mathrm{Se})\right]$ and $\psi_{66}$ [HOMO- $\left.1: \pi(\mathrm{Se}-\mathrm{Se})\right]$ at the singlet state. The MO presentation in Figure 8 is essentially the same as the $\psi_{42} \rightarrow \psi_{44}$ and $\psi_{43} \rightarrow \psi_{44}$ transitions in ${ }^{1} J_{\mathrm{PSO}}(\mathrm{Se}, \mathrm{Se}: \mathbf{1 a})$ at $\phi=0^{\circ}$ in Figure 4, although $\psi_{67}$ (2a) and $\psi_{66}(\mathbf{2 a})$ contain the $\pi(\mathrm{Nap})$ character. Large ${ }^{1} J_{\text {PSO }}$ (Se, Se: 2 ) and small ${ }^{1} J_{\text {obsd }}$ (Se, Se: 1$)$ are well understood by the $\phi$ dependence in the calculated ${ }^{1} J$ (Se, Se: 1a) values.

\section{Conclusion}

Nuclear spin-spin coupling constants $(J)$ provide highly important information around coupled nuclei, containing 


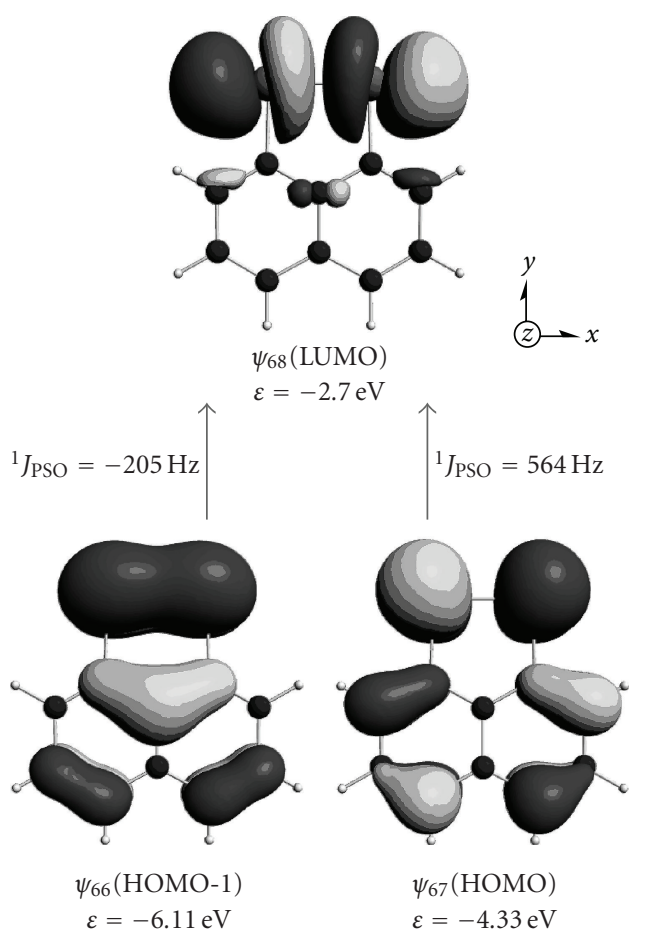

Figure 8: MO analysis of ${ }^{1} J_{\mathrm{PSO}}$ (Se, Se: $2 \mathbf{a}$ ): main contributions from the $\psi_{67}(\mathrm{HOMO}) \rightarrow \psi_{68}(\mathrm{LUMO})$ and $\psi_{66} \rightarrow \psi_{68}$ transitions are depicted.

strongly bonded and weakly interacting states. The ${ }^{1} J(\mathrm{Se}$, Se) values are analyzed as the first step to investigate the nature of the bonded and nonbonded interactions between the Se atoms through ${ }^{n} J(\mathrm{Se}, \mathrm{Se})$. QC calculations are necessary for the analysis and the interpretation of the $J$ values with physical meanings. Calculated ${ }^{n} J_{\mathrm{TL}}$ are composed of the contributions from ${ }^{n} J_{\mathrm{DSO}},{ }^{n} J_{\mathrm{PSO}},{ }^{n} J_{\mathrm{SD}}$, and ${ }^{n} J_{\mathrm{FC}}$. The decomposition helps us to consider the mechanisms of the spin-spin couplings, which are closely related to the electronic structures of compounds. Main contributions are evaluated separately from each $\psi_{i}$ and each $\psi_{i} \rightarrow \psi_{a}$ transition, where $\psi_{i}$ and $\psi_{a}$ are occupied and unoccupied MO's, respectively.

${ }^{1} J$ (Se, Se) is calculated modeled by MeSeSeMe (1a), which shows the typical torsional angular dependence of $\phi\left(\mathrm{C}_{\mathrm{Me}} \mathrm{SeSeC} \mathrm{Me}_{\mathrm{Me}}\right)$. The dependence explains well ${ }^{1} J_{\mathrm{obsd}}(\mathrm{Se}$, Se) of small values for $\mathrm{RSeSeR}^{\prime}$ (1) and large values for $4-\mathrm{Y}-1,8-\mathrm{Se}_{2} \mathrm{C}_{10} \mathrm{H}_{5}$ (2) which correspond to symperiplanar diselenides. ${ }^{1} J_{\mathrm{TL}}$ (Se, Se: 2 ) are confirmed to be controlled by $\mathrm{Q} n(\mathrm{Se}) .{ }^{1} J_{\mathrm{TL}}$ (Se, Se: 2 ) are demonstrated to be smaller when $\mathrm{Q} n(\mathrm{Se})$ becomes larger, experimentally and theoretically. The PSO terms contribute predominantly to ${ }^{1} J(\mathrm{Se}, \mathrm{Se})$. The contributions are analyzed separately from each $\psi_{i}$ and each $\psi_{i} \rightarrow \psi_{a}$ transition. The MO description of each transition enables us to recognize and visualize clearly the origin and the mechanisms of the indirect nuclear spinspin couplings. Important properties of molecules, such as electronic structures, will be clarified by elucidating the mechanisms of the spin-spin couplings on the basis of the MO theory.

\section{Acknowledgments}

This work was partially supported by a Grant-in-Aid for Scientific Research (nos. 16550038, 19550041, and 20550042) from the Ministry of Education, Culture, Sports, Science, and Technology, Japan.

\section{References}

[1] M. Karplus, "Contact electron-spin coupling of nuclear magnetic moments," The Journal of Chemical Physics, vol. 30, no. 1, pp. 11-15, 1959.

[2] M. Karplus, "Vicinal proton coupling in nuclear magnetic resonance," Journal of the American Chemical Society, vol. 85, no. 18, pp. 2870-2871, 1963.

[3] M. Barfield and W. B. Smith, "Internal H-C-C angle dependence of vicinal $1 \mathrm{H}-1 \mathrm{H}$ coupling constants," Journal of the American Chemical Society, vol. 114, no. 5, pp. 1574-1581, 1992.

[4] F. B. Mallory, C. W. Mallory, K. E. Butler, et al., "Nuclear spinspin coupling via nonbonded interactions. 8. The distance dependence of through-space fluorine-fluorine coupling," Journal of the American Chemical Society, vol. 122, no. 17, pp. 4108-4116, 2000.

[5] T. Helgaker, M. Jaszuński, and K. Ruud, "Ab initio methods for the calculation of NMR shielding and indirect spin-spin coupling constants," Chemical Reviews, vol. 99, no. 1, pp. 293352, 1999.

[6] H. Fukui, "Theory and calculation of nuclear spin-spin coupling constants," Progress in Nuclear Magnetic Resonance Spectroscopy, vol. 35, no. 3, pp. 267-294, 1999.

[7] M. Bienati, C. Adamo, and V. Barone, "Performance of a new hybrid Hartree-Fock/Kohn-Sham model (B98) in predicting vibrational frequencies, polarisabilities and NMR chemical shifts," Chemical Physics Letters, vol. 311, no. 1-2, pp. 69-76, 1999.

[8] R. H. Contreras, J. E. Peralta, C. G. Giribet, M. C. Ruiz de Azua, and J. C. Facelli, "Advances in theoretical and physical aspects of spin-spin coupling constants," in Annual Reports on NMR Spectroscopy, G. A. Webb, Ed., vol. 41, pp. 55-184, Academic Press, New Yrok, NY, USA, 2000.

[9] T. M. Klapötke and M. Broschag, Eds., Compilation of Reported ${ }^{77}$ Se NMR Chemical Shifts, John Wiley-VCH, New York, NY, USA, 1996.

[10] T. Helgaker and M. Pecul, "Spin-spin coupling constants with HF and DFT method," in Calculations of NMR and EPR Parameters: Theory and Applications, M. Kaupp, M. Bühl, and V. G. Malkin, Eds., chapter 7, Wiley-VCH, Weinheim, Germany, 2004.

[11] J. Meinwald, D. Dauplaise, F. Wudl, and J. J. Hauser, "Peribridged naphthalenes from 1,8-dilithionaphthalene," Journal of the American Chemical Society, vol. 99, no. 1, pp. 255-257, 1977.

[12] J. Meinwald, D. Dauplaise, and J. Clardy, "Peri-bridged naphthalenes. 2. Unsymmetrical diatomic chalcogen bridges," Journal of the American Chemical Society, vol. 99, no. 23, pp. 7743-7744, 1977.

[13] D. Dauplaise, J. Meinwald, J. C. Scott, H. Temkin, and J. Clardy, "Synthesis and properties of chalcogen-bridged naphthalenes: a new series of electron donors," Annals of the New York Academy of Sciences, vol. 313, no. 1, pp. 382-394, 1978. 
[14] K. Yui, Y. Aso, and T. Otsubo, "Syntheses and properties of binaphtho[1,8-del-1,3-dithiin-2-ylidene and its selenium analogue," Chemistry Letters, vol. 15, no. 4, pp. 551-554, 1986.

[15] Y. Aso, K. Yui, T. Miyoshi, T. Otsubo, F. Ogura, and J. Tanaka, "Dichalcogen-bridged acenaphthenes as new electron donors," Bulletin of the Chemical Society of Japan, vol. 61, no. 6, pp. 2013-2018, 1988.

[16] J. A. Anderson, J. D. Odom, and A. J. Zozulin, "Preparation of unsymmetrical alkyl methyl and alkyl phenyl diselenides and determination of their selenium-77 chemical shifts and 77Se-77Se spin-spin coupling constants," Organometallics, vol. 3, no. 10, pp. 1458-1465, 1984.

[17] G. Llabres, M. Baiwir, J.-L. Piette, and L. Christiaens, "77Se, $13 \mathrm{C}$ and $1 \mathrm{H}$ NMR investigations on ortho-carbonyl benzeneselenenyl derivatives," Organic Magnetic Resonance, vol. 15, no. 2, pp. 152-154, 1981.

[18] W. Nakanishi and S. Hayashi, "Torsional angular dependence of ${ }^{1} J(\mathrm{Se}, \mathrm{Se})$ and fermi contact control of ${ }^{4} J(\mathrm{Se}, \mathrm{Se})$ : analysis of ${ }^{n} J(\mathrm{Se}, \mathrm{Se})(n=1-4)$ based on molecular orbital theory," Chemistry: A European Journal, vol. 14, no. 18, pp. 5645-5655, 2008.

[19] G. te Velde, F. M. Bickelhaupt, E. J. Baerends, et al., "Chemistry with ADF," Journal of Computational Chemistry, vol. 22, no. 9, pp. 931-967, 2001.

[20] C. Fonseca Guerra, J. G. Snijders, G. Te Velde, and E. J. Baerends, "Towards an order-N DFT method," Theoretical Chemistry Accounts, vol. 99, no. 6, pp. 391-403, 1998.

[21] E. J. Baerends, J. Autschbach, A. Bérces, et al., "ADF 2008.01, SCM, Theoretical Chemistry," Vrije Universiteit, Amsterdam, The Netherlands, http://www.scm.com/.

[22] E. van Lenthe and E. J. Baerends, "Optimized Slater-type basis sets for the elements 1-118," Journal of Computational Chemistry, vol. 24, no. 9, pp. 1142-1156, 2003.

[23] D. P. Chong, E. van Lenthe, S. Van Gisbergen, and E. J. Baerends, "Even-tempered slater-type orbitals revisited: from hydrogen to krypton," Journal of Computational Chemistry, vol. 25, no. 8, pp. 1030-1036, 2004.

[24] M. J. Frisch, G. W. Trucks, H. B. Schlegel, et al., GAUSSIAN 03 (Revision D.05), Gaussian, Inc., Pittsburgh, Pa, USA, 2004.

[25] R. C. Binning Jr. and L. A. Curtiss, "Compact contracted basis sets for third-row atoms: Ga-Kr," Journal of Computational Chemistry, vol. 11, no. 10, pp. 1206-1216, 1990.

[26] L. A. Curtiss, M. P. McGrath, J.-P. Blaudeau, N. E. Davis, R. C. Binning Jr., and L. Radom, "Extension of Gaussian-2 theory to molecules containing third-row atoms Ga-Kr," The Journal of Chemical Physics, vol. 103, no. 14, pp. 6104-6113, 1995.

[27] M. P. McGrath and L. Radom, "Extension of Gaussian-1 (G1) theory to bromine-containing molecules," The Journal of Chemical Physics, vol. 94, no. 1, pp. 511-516, 1991.

[28] T. Clark, J. Chandrasekhar, G. W. Spitznagel, and P. Von Ragué Schleyer, "Efficient diffuse function-augmented basis sets for anion calculations-III: the $3-21+\mathrm{G}$ basis set for first-row elements, Li-F," Journal of Computational Chemistry, vol. 4, no. 3, pp. 294-301, 1983.

[29] A. D. Becke, "Density-functional exchange-energy approximation with correct asymptotic behavior," Physical Review A, vol. 38, no. 6, pp. 3098-3100, 1988.

[30] A. D. Becke, "Density-functional thermochemistry-III: the role of exact exchange," The Journal of Chemical Physics, vol. 98, no. 7, pp. 5648-5652, 1993.

[31] C. Lee, W. Yang, and R. G. Parr, "Development of the ColleSalvetti correlation-energy formula into a functional of the electron density," Physical Review B, vol. 37, no. 2, pp. 785789, 1988.
[32] B. Miehlich, A. Savin, H. Stoll, and H. Preuss, "Results obtained with the correlation energy density functionals of becke and Lee, Yang and Parr," Chemical Physics Letters, vol. 157, no. 3, pp. 200-206, 1989.

[33] E. van Lenthe, E. J. Baerends, and J. G. Snijders, "Relativistic regular two-component Hamiltonians," The Journal of Chemical Physics, vol. 99, no. 6, pp. 4597-4610, 1993.

[34] E. van Lenthe, E. J. Baerends, and J. G. Snijders, "Relativistic total energy using regular approximations," The Journal of Chemical Physics, vol. 101, no. 11, pp. 9783-9792, 1994.

[35] E. van Lenthe, A. Ehlers, and E. J. Baerends, "Geometry optimizations in the zero order regular approximation for relativistic effects," The Journal of Chemical Physics, vol. 110, no. 18, pp. 8943-8953, 1999.

[36] J. Autschbach and T. Ziegler, "Nuclear spin-spin coupling constants from regular approximate relativistic density functional calculations-I: formalism and scalar relativistic results for heavy metal compounds," The Journal of Chemical Physics, vol. 113, no. 3, pp. 936-947, 2000.

[37] J. Autschbach and T. Ziegler, "Nuclear spin-spin coupling constants from regular approximate relativistic density functional calculations-II: spin-orbit coupling effects and anisotropies," The Journal of Chemical Physics, vol. 113, no. 21, pp. 94109418, 2000.

[38] A. E. Reed, R. B. Weinstock, and F. Weinhold, "Natural population analysis," The Journal of Chemical Physics, vol. 83, no. 2, pp. 735-746, 1985.

[39] J. E. Carpenter and F. Weinhold, "Analysis of the geometry of the hydroxymethyl radical by the "different hybrids for different spins" natural bond orbital procedure," Journal of Molecular Structure: THEOCHEM, vol. 169, pp. 41-62, 1988.

[40] E. D. Glendening, A. E. Reed, J. E. Carpenter, and F. Weinhold, "NBO Ver. 3.1". 


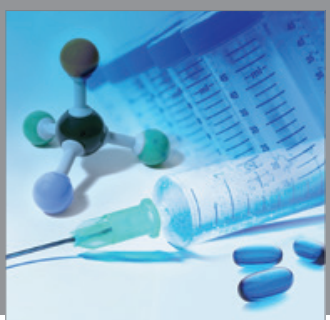

International Journal of

Medicinal Chemistry

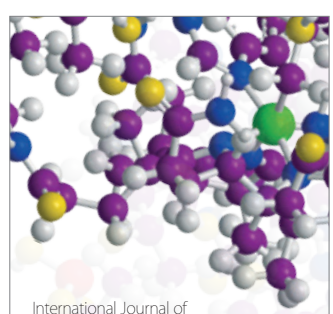

Carbohydrate Chemistry

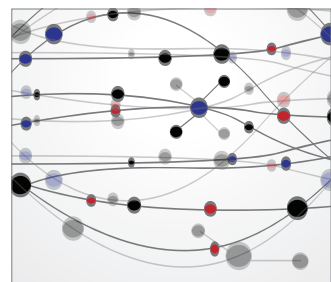

The Scientific World Journal
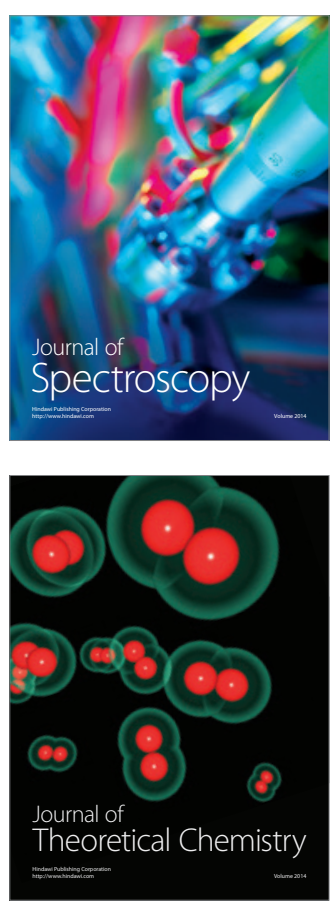
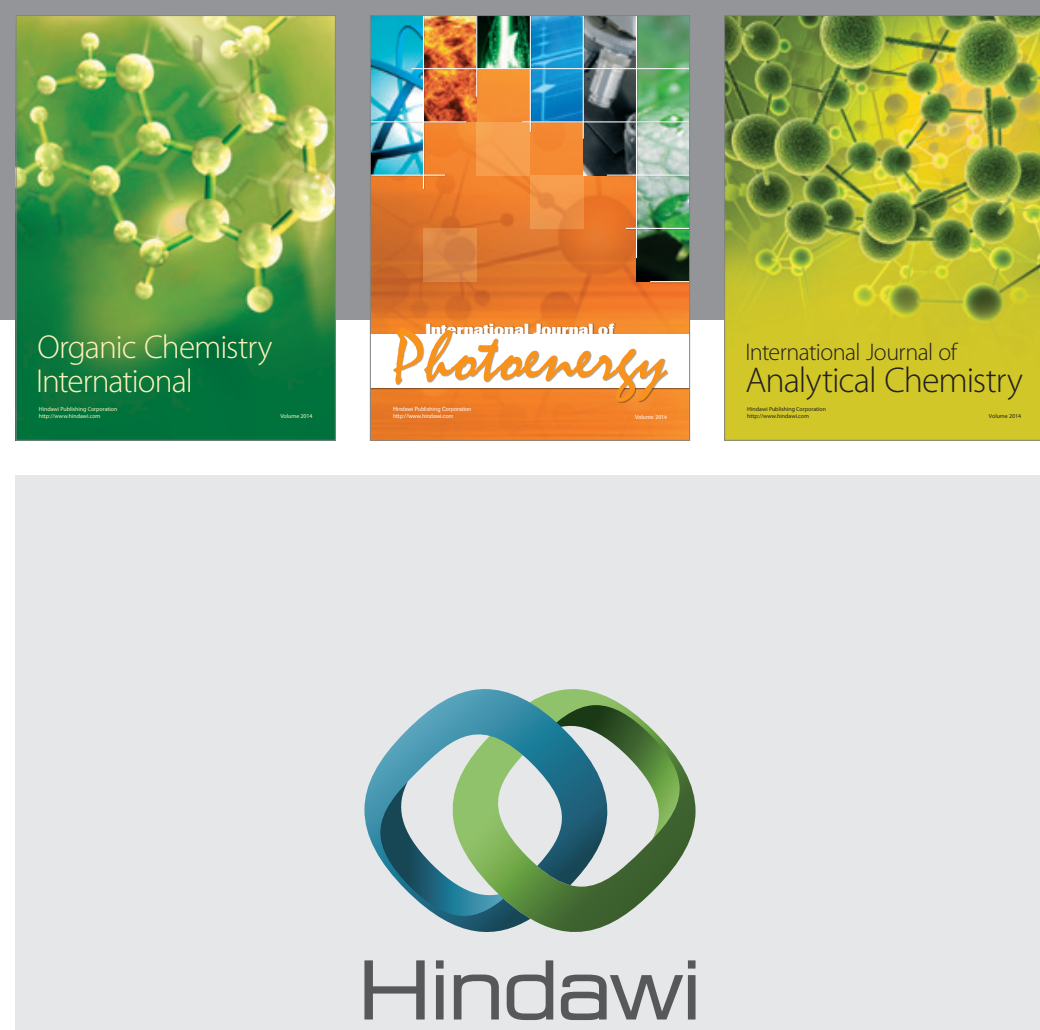

Submit your manuscripts at

http://www.hindawi.com
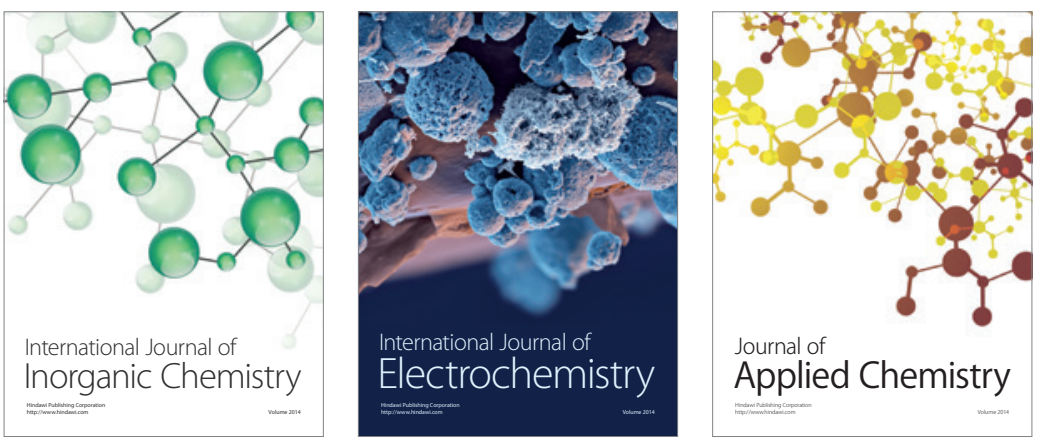

Journal of

Applied Chemistry
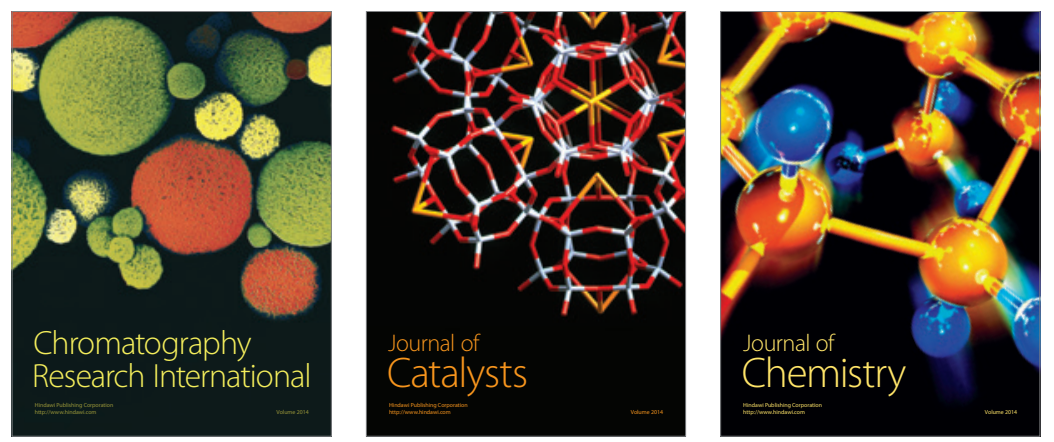
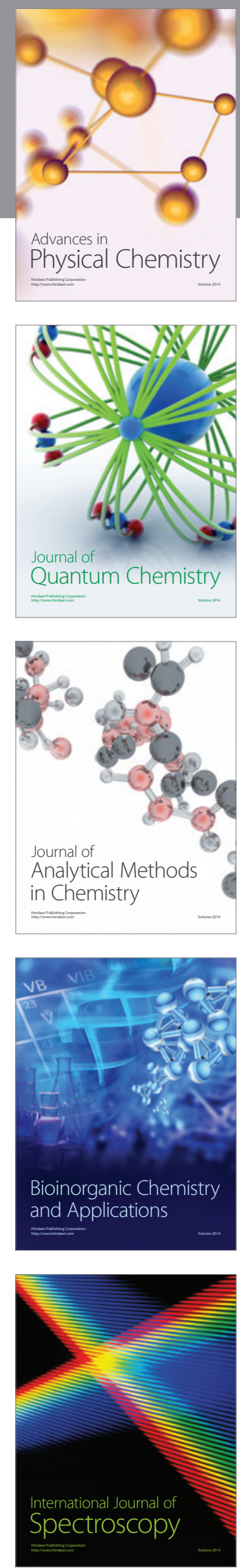